\title{
Properties of Polystyrene Clay Nanocomposites Prepared Using Two New Imidazolium Surfactants
}

\author{
Giovanna Di Pasquale ${ }^{1}$ and Antonino Pollicino ${ }^{2}$ \\ ${ }^{1}$ Department of Chemical Science, University of Catania and INSTM UdR Catania, Viale A. Doria 6, Catania, Italy \\ ${ }^{2}$ Department of Civil Engineering and Architecture, University of Catania and INSTM UdR Catania, Viale A. Doria 6, Catania, Italy \\ Correspondence should be addressed to Antonino Pollicino; apollicino@dii.unict.it
}

Received 28 July 2016; Revised 9 November 2016; Accepted 22 December 2016; Published 26 January 2017

Academic Editor: Luca Valentini

Copyright (c) 2017 Giovanna Di Pasquale and Antonino Pollicino. This is an open access article distributed under the Creative Commons Attribution License, which permits unrestricted use, distribution, and reproduction in any medium, provided the original work is properly cited.

\begin{abstract}
Montmorillonite/polystyrene nanocomposites were prepared by in situ photopolymerization of styrene in the presence of $2 \%$ by weight of clay organomodified by two new imidazolium surfactants having in their structure an alkyl chain with 20 or 22 carbon atoms, respectively. Thermogravimetry showed that the new surfactants are more thermally stable than conventional alkylammonium surfactants. The properties of the obtained nanocomposites were compared with those of pristine polystyrene, with those of a microcomposite obtained by in situ polymerization of styrene in the presence of unmodified clay, and with those of a nanocomposite obtained starting from an organomodified clay with a short alkyl chain (12 carbon atoms) imidazolium surfactant. XRD, TEM, and rheological analysis showed that the clay/PS nanocomposites have a mixture of intercalated and partially exfoliated structure layers, where the higher the surfactant alkyl chain length, the higher the exfoliation degree. Kinetics curve of accelerated UV aging, obtained by following through infrared spectroscopy the increase of carbonyl functions during aging, showed that the rate of photooxidation of clay containing samples is higher than neat polystyrene. The rate is higher as a function of the degree of dispersion of the filler in the polymer matrix.
\end{abstract}

\section{Introduction}

In recent decades there has been a considerable interest in polymer nanocomposites [1-5]. The interest has involved both academic and industrial communities because of the significant application perspectives that the development of this new class of materials made to glimpse. The high performances that the filler dispersion at the nanometer level allows to achieve affect physical, mechanical, optical, and economic fields [6-8].

The predictions of using these materials on large-scale have been progressively revised downwards, and the estimate of 2002 of reaching, in the US alone, a turnover of $\$ 4$ billion for 2010 [9] was recently updated [10] and global market consumption of nanocomposites in 2013 reached 190 ktons, or $\$ 1.2$ billion, and now is expected to grow in unit terms from nearly 225 ktons in 2014 to nearly 585 ktons, or $\$ 4.2$ billion, in 2019, with a compound annual growth rate (CAGR) of $21.1 \%$ for the period from 2014 to 2019. The postposition of predictions made in 2002 is in part due to emerging problems relating to the production and durability of these materials.

Among the various classes of polymeric nanocomposites, the polymer-clay ones have seemed the most promising in relation to production costs and achievable performances, and clay nanocomposites accounted for more than $50 \%$ of total nanocomposite consumption by value in 2010 . Their market share is expected to increase to approximately $58 \%$ in 2016. The raw materials from which the filler is obtained are widely available and the best performance aspects relate to the mechanical properties, such as Young's modulus and toughness, and, among others, to those relating to a particular aspect watched with interest by the market of plastic materials, that is, the possibility of contributing to replace the halogenated flame retardant additives to enhance fire resistance of plastic materials [11].

The research has shown, however, that in order to achieve a substantial improvement of the mechanical performance is necessary to obtain a nanometric dispersion of individual 
clay layers, obtaining the so-called exfoliated structure, rather than having the more easily obtainable but less performing morphologies, that is, the intercalated ones, in which the layers remain well ordered and the polymer chains are inserted into the gallery space of the silicate $[12,13]$.

To obtain intercalated and/or exfoliated structures it is necessary to organically modify the clay in order to increase the affinity with the polymer matrix. The organic modification of the clay is most commonly made with quaternary ammonium salts. Due to this organic modification the thermal stage of the production process becomes even more relevant. In fact, alongside the well-known steps that must be taken because of the relative thermal stability of the polymer matrices, it is also necessary to pay attention to the thermal degradation processes faced by the surfactants used in the organic modification of the clay. The quaternary ammonium salts, in fact, begin to decompose, resulting in a Hoffman elimination [14] that produces amines and volatile olefins, in a range of temperatures ranging from 150 [15] to $180^{\circ} \mathrm{C}$ [16]. This decomposition process involves the collapse of the clay layers that prevents the achievement of the desired exfoliated structures [17]. To overcome this problem, cationic surfactants, such as phosphonium [18, 19], pyridinium [20], and imidazolium [21, 22], have been used to modify layered silicate because of their higher thermal stabilities.

Another issue that has emerged from the study of this class of nanocomposites is that the presence of the nanofiller determines the deterioration of the resistance of the polymer matrix to UV photooxidation [23-25]. In literature, several authors have tried to explain the mechanism of this decrease of durability and various explanations have been proposed. Some authors consider, for example, that this phenomenon is attributed to the presence of the surfactant, while others attribute it to the catalytic action of metal ions present in the clay layers $[26,27]$. We have contributed to this debate and our previous studies have shown that a lower stability to $\mathrm{UV}$ radiation is also determined by the presence of the clay only and may also be in relation to the degree of exfoliation achieved in the nanocomposite [28].

Continuing our studies we now present the results obtained using two new imidazole surfactants with a thermal stability higher than the one of conventional surfactants based on quaternary ammonium salts, and that, due to the long alkyl chains present in their structure, should allow reaching a high degree of exfoliation. Using these new surfactants we have realized the organic modification of montmorillonite and with the obtained clay we have prepared, by in situ polymerization, polystyrene-montmorillonite nanocomposites with a clay concentration of $2 \%$ by weight. The nanocomposites were characterized by GPC analysis to determine the average molecular weight of the matrix, XRD, TEM, and rheological analysis to obtain information on the relative degree of exfoliation. FT-IR spectroscopy was used to follow accelerated UV aging of pristine PS and of nanocomposites.

\section{Materials and Methods}

The chemicals used in this study were acquired from Aldrich Chemical Co. The MMT (Na/MMT) is a fine powder with a particle size of $10-15 \mu \mathrm{m}$ in a dry state and a cation exchange capacity (CEC) of $100 \mathrm{mEq} / 100 \mathrm{~g}$. Styrene monomer was purified using an inhibitor removal column, also acquired from Aldrich. AIBN was purified crystallizing it twice from dry ethanol at a temperature lower than $40^{\circ} \mathrm{C}$ and out of direct light.

2.1. Instruments. ${ }^{1} \mathrm{H}-\mathrm{NMR}$ spectra were recorded in a Varian Unity Inova $500 \mathrm{MHz}$ spectrometer, without an internal standard, at room temperature, using DMSO- $\mathrm{d}_{6}$ (deuterated dimethyl sulfoxide) and $\mathrm{CDCl}_{3}$ (deuterated chloroform) as a solvent.

Thermal degradations were performed in a Mettler TA 3000 thermogravimetric analyzer coupled with a Mettler TC $10 \mathrm{~A}$ processor. Degradations were performed in dynamic heating conditions, from 35 up to $600^{\circ} \mathrm{C}$, in flowing nitrogen $\left(0.02 \mathrm{~L} \mathrm{~min}^{-1}\right)$ or static air at a heating rate of $10^{\circ} \mathrm{C} \mathrm{min}^{-1}$. The thermogravimetric (TGA) and differential thermogravimetric (DTGA) curves were immediately printed at the end of each experiment and the mass of sample at various temperatures was then transferred to a PC. These data were later used to plot the percentage of undegraded sample $(1-D) \%$ as a function of temperature, where $D=\left(W_{o}-W\right) / W_{o}$, and $W_{o}$ and $W$ were the masses at the starting point and during scanning.

XRD measurements were recorded on a Bruker-AXS D5005 $\theta-\theta$ X-ray diffractometer, using $\mathrm{Cu} \mathrm{K}_{\alpha}$ radiation operating at $20 \mathrm{kV}$ and $30 \mathrm{~mA}$.

The molecular weight results were determined using an HP 1100 GPC instrument, equipped with a refractive index detector, operating at $30^{\circ} \mathrm{C}$, using tetrahydrofuran (THF) as carrier at a flow rate of $1 \mathrm{~mL} \mathrm{~min}^{-1}$. Separation was accomplished using a PLgel $5 \mu \mathrm{m}$ mixed-D column connected with a PLgel $5 \mu \mathrm{m} 500 \AA$ column (Polymer Labs). The measurement utilized a refractive index detector and toluene as internal standard. Solution concentrations were $2 \mathrm{mg} / \mathrm{mL}$ in THF; they were filtered through $0.45 \mu \mathrm{m}$ PTFE membranes and injected into the columns in $20 \mu \mathrm{m}$ aliquots. Calibration was performed using narrow polydispersity polystyrene standards in weight average molecular weights in the range 2500400000 Da.

For rheological analysis, sample disks were produced by compression and performed with a rheometer ARES (Advanced Rheometric Expansion System), in the plate-plate geometry, using plates of $25 \mathrm{~mm}$ in diameter and a sample thickness of $\sim 1 \mathrm{~mm}$. The measurements were conducted under isothermal and variable frequency (from 0.1 to $100 \mathrm{rad} / \mathrm{s}$ ). The temperatures used for the tests ranged from $170^{\circ} \mathrm{C}$ to $240^{\circ} \mathrm{C}$ and an amplitude of deformation of $1 \%$ has been applied to obtain a linear viscoelastic response.

Films of the samples with a thickness of 25, 50, and $100 \mu \mathrm{m}$ were obtained by means of a Graseby Specac P/N15800 press, heating the material, reducing it to powder, at $170^{\circ} \mathrm{C}$ for 2 minutes and then applying a force of 2 tons for another 2 minutes.

The accelerated exposure device used in the experiments was a Xenotest Alpha (Atlas), equipped with a Xenon lamp set up for simulated sunlight exposure conditions $(\lambda \geq 300 \mathrm{~nm})$ 


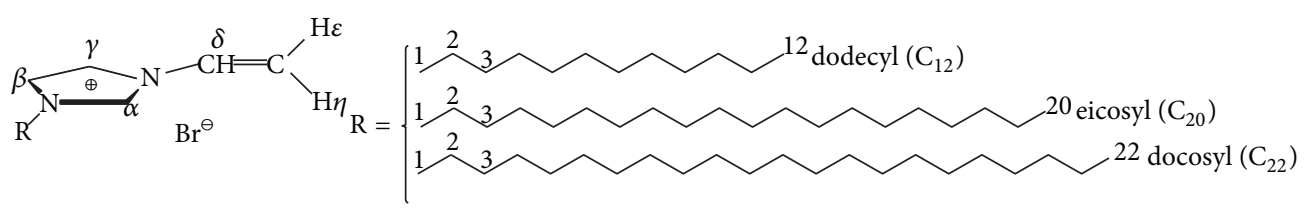

Scheme 1: Structures of surfactants $\mathrm{C}_{12}, \mathrm{C}_{20}$, and $\mathrm{C}_{22}$.

with six infrared filter plates and one dark UV filter glass inserted in the filter lantern. The irradiance was $80 \mathrm{~W} / \mathrm{m}^{2}$. The black panel temperature was $60^{\circ} \mathrm{C}$ and the relative humidity was $60 \%$, without rain. The specimen holders turned on their own axis, which resulted in alternating dark/light cycles. The exposures were conducted for $400 \mathrm{~h}$ and the chemical degradations were periodically checked by FT-IR.

FT-IR spectra were recorded from exposed sample films by a Perkin-Elmer Spectrum-100 spectrophotometer. They were recorded from $4000 \mathrm{~cm}^{-1}$ to $400 \mathrm{~cm}^{-1}$ with a resolution of $2.0 \mathrm{~cm}^{-1}$. To compare the spectra of different nanocomposites an internal calibration of the thickness of each sample was performed by measuring the absorbance at $539 \mathrm{~cm}^{-1}$.

2.2. Synthesis of Imidazolium Salts. Imidazolium salts $\left(\mathrm{C}_{20}\right.$ and $\mathrm{C}_{22}$, Scheme 1) were prepared as follows: $0.02237 \mathrm{~mol}$ of alkyl bromide, $0.02125 \mathrm{~mol}$ of 1-vinylimidazole, and $5.000 \mathrm{~mL}$ of ethyl acetate were put in a $50.00 \mathrm{~mL}$ round-bottom flask and stirred at room temperature for $12 \mathrm{hrs}$ in inert atmosphere. After heating to $55^{\circ} \mathrm{C}$, it was allowed to react for $24 \mathrm{hrs}$ to give, after cooling, a white precipitate of the imidazolium salt. This solid was filtered, washed several time with ethyl acetate to remove the unreacted compounds, and finally dried under vacuum at $45^{\circ} \mathrm{C}$. The synthesized products were characterized via mass spectroscopy, ${ }^{1} \mathrm{H}$ NMR spectroscopy, and elemental analysis.

$C_{20}: \mathrm{C}_{25} \mathrm{H}_{47} \mathrm{~N}_{2} \mathrm{Br}$ (455.56): Calcd. C 65.91, H 10.40, N 6.15; Found C 65.60, H 10.50, N 6.09

${ }^{1} \mathrm{H}$ NMR (DMSO-d 6 ): $\delta=0.88\left(\mathrm{t}, \mathrm{H}^{20}\right), 1.34\left(\mathrm{~m}, \mathrm{H}^{3}-\right.$ $\left.\mathrm{H}^{19}\right), 1.96\left(\mathrm{~m}, \mathrm{H}^{2}\right), 4.41\left(\mathrm{t}, \mathrm{H}^{1}\right), 5.42\left(\mathrm{dd}, \mathrm{H}^{\varepsilon}\right), 5.91(\mathrm{dd}$, $\left.\mathrm{H}^{\eta}\right), 7.27\left(\mathrm{dd}, \mathrm{H}^{\delta}\right), 7.51\left(\mathrm{~m}, \mathrm{H}^{\gamma}\right.$ and $\left.\mathrm{H}^{\beta}\right), 11.35\left(\mathrm{~s}, \mathrm{H}^{\alpha}\right)$.

MS: $m / z=375.3\left(\mathrm{M}^{+}\right)$.

$C_{22}: \mathrm{C}_{27} \mathrm{H}_{51} \mathrm{~N}_{2} \mathrm{Br}$ (483.61): Calcd. C 67.06, H 10.63, N 5.79; Found C 66.9, H 10.49, N 5.76.

${ }^{1} \mathrm{H}$ NMR (DMSO- $\left.\mathrm{d}_{6}\right): \delta=0.88\left(\mathrm{t}, \mathrm{H}^{22}\right), 1.25\left(\mathrm{~m}, \mathrm{H}^{3}-\right.$ $\left.\mathrm{H}^{21}\right), 1.96\left(\mathrm{~m}, \mathrm{H}^{2}\right), 4.41\left(\mathrm{t}, \mathrm{H}^{1}\right), 5.43\left(\mathrm{dd}, \mathrm{H}^{\varepsilon}\right), 5.92(\mathrm{dd}$, $\left.\mathrm{H}^{\eta}\right), 7.30\left(\mathrm{dd}, \mathrm{H}^{\delta}\right), 7.53\left(\mathrm{~m}, \mathrm{H}^{\gamma}\right.$ and $\left.\mathrm{H}^{\beta}\right), 11.30\left(\mathrm{~s}, \mathrm{H}^{\alpha}\right)$.

MS: $m / z=403.4\left(\mathrm{M}^{+}\right)$.

2.3. Preparation of $o-M M T$. An aqueous suspension of $2.088 \mathrm{~g}$ of prewashed Na/MMT in $200.0 \mathrm{~mL}$ of deionized water was added to a solution obtained dissolving $2.506 \mathrm{mmol}$ of imidazolium salt in $10.00 \mathrm{~mL}$ of a $50: 50 \mathrm{mix}-$ ture of ethanol and deionized $\mathrm{H}_{2} \mathrm{O}$ at $50^{\circ} \mathrm{C}$. After the solution was stirred in inert atmosphere for $6 \mathrm{hrs}$ at $50^{\circ} \mathrm{C}$, the white powder was filtered, washed several times with a mixture of ethanol and deionized water until no bromide ion could be detected by an $\mathrm{AgNO}_{3}$ aqueous solution, and then dried in a vacuum oven overnight at room temperature.

2.4. Preparation of PS/o-MMT Nanocomposites. As a typical procedure for the preparation of PS materials via in situ free radical polymerization, an appropriate amount of organophilic clay, calculated by $2 \mathrm{wt} \%(0.240 \mathrm{~g})$, with respect to styrene was thoroughly dispersed in $12.00 \mathrm{~g}$ of styrene monomer. First, the suspension was stirred at room temperature under flowing $\mathrm{N}_{2}$ gas until it became homogeneous (7 hrs); then it was sonicated for $1 \mathrm{~h}$; finally $0.0600 \mathrm{~g}(0.5 \mathrm{wt} \%)$ of AIBN initiator was added to monomer clay mixture. The tube was degassed by three freeze-thaw cycles, sealed at $0.01 \mathrm{mmHg}$, and placed in a constant temperature bath at $60^{\circ} \mathrm{C}$ for $16 \mathrm{hrs}$ to obtain PS/clay nanocomposites. A bulk polymerization of styrene was carried out at the same conditions used for the nanocomposites except for the absence of the clay.

The samples used for GPC measurements were obtained as follows: the nanocomposites were extracted using toluene at room temperature and were repeatedly filtered to ensure the removal of the clay. The PSs obtained by precipitation in methanol were used to prepare the solutions.

\section{Results and Discussion}

The studied nanocomposite samples were prepared by polymerization in situ of styrene in the presence of $2 \%$ by weight of organically modified montmorillonite with imidazole cations (Scheme 1 ) and $0.5 \%$ of AIBN.

In this regard, we proceeded to the synthesis of two new imidazole surfactants $1 \mathrm{H}$-imidazolium, 1-eicosyl-3-ethenyl and $1 \mathrm{H}$-Imidazolium, and 1-docosyl-3-ethenyl $\left(\mathrm{C}_{20}\right.$ and $\mathrm{C}_{22}$, resp.) with the purpose of reaching a higher degree of exfoliation in nanocomposite by the increased baseline distance between the lamellae of modified montmorillonite. These two new surfactants, bearing aliphatic chains, respectively, of 20 or 22 carbon atoms linked to one of the nitrogen atoms of the imidazole ring and obtained according to the procedures described in the materials and methods part, were characterized by ${ }^{1} \mathrm{H}$ NMR spectroscopy (Figure 1, Scheme 1), Mass Spectrometry (MS), and elemental analysis (EA). Both MS and EA results fit the data associated with the surfactant structure that has been definitively confirmed by NMR results. The ${ }^{1} \mathrm{H}$ NMR spectra of $\mathrm{C}_{20}$ and $\mathrm{C}_{22}$ showed that the signals relative to $\mathrm{H}^{\alpha}, \mathrm{H}^{\beta}$, and $\mathrm{H}^{\gamma}$ were shifted downfield of about $1 \mathrm{ppm}$ with respect to the 1-vinylimidazole ones. A similar result was observed also for the signal associated with $\mathrm{H}^{\delta}$ (from $7.16 \delta$ to $7.30 \delta$ ) and for the double doublets relative 


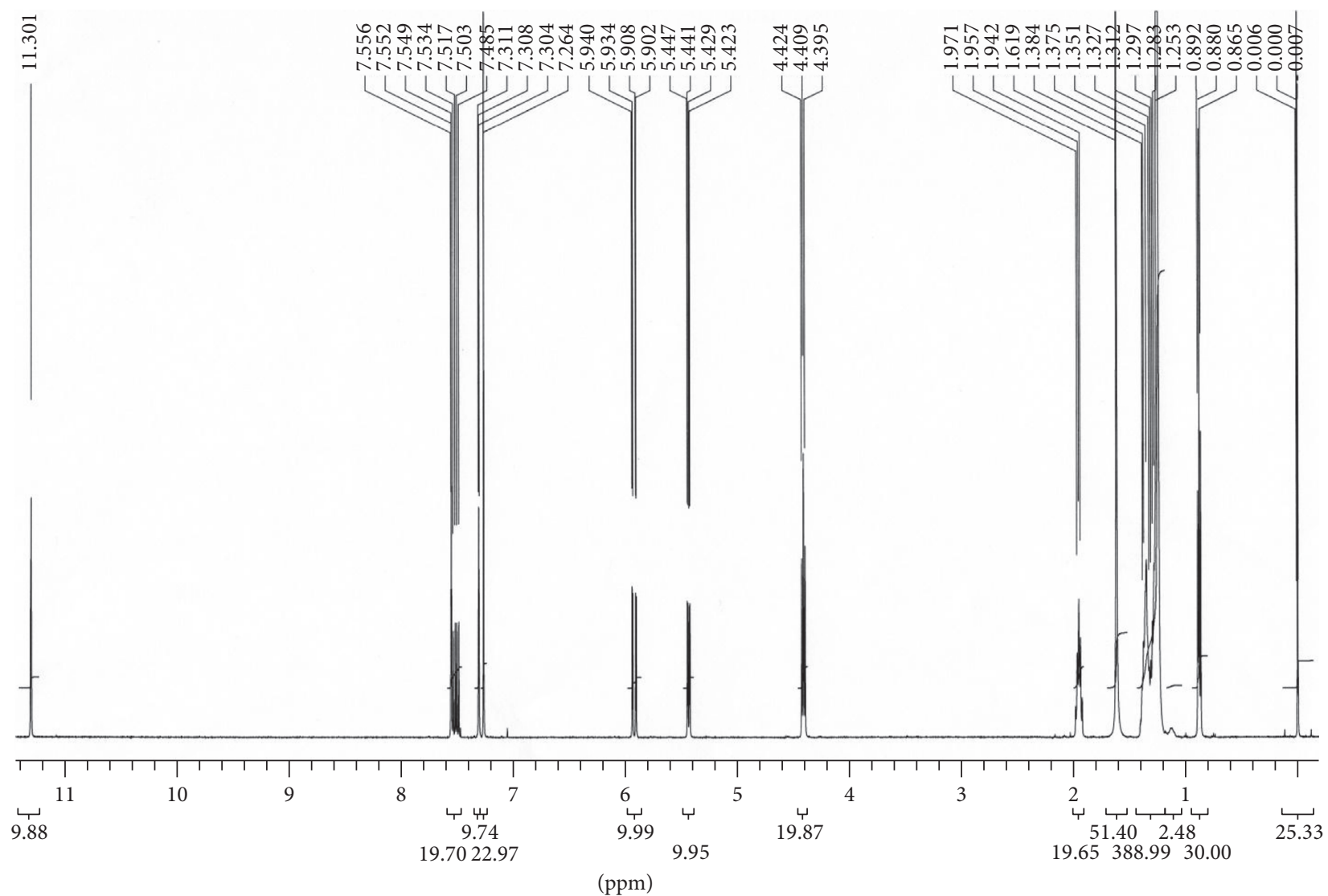

FIgURE 1: ${ }^{1} \mathrm{H}$ NMR spectrum of $\mathrm{C}_{22}$ imidazolium surfactant.

to $\mathrm{H}^{\varepsilon}$ and $\mathrm{H}^{\eta}$ (from $4.85 \delta$ and $5.47 \delta$ to $5.43 \delta$ and 5.92 $\delta$, resp.). These shifts are in agreement with the cationic character of $\mathrm{C}_{20}$ and $\mathrm{C}_{22}$.

In order to check that the two new imidazole surfactants have a thermal stability higher than the one of conventional surfactants based on quaternary ammonium salts, the cation thermal stabilities were studied by TGA in both flowing nitrogen and static air atmosphere. In all the samples studied by thermogravimetry a weight loss was detected in the range $80-120^{\circ} \mathrm{C}$. It corresponds to the loss of adsorbed water into the sample. Since this kind of water is not a decomposition product, its presence can be neglected. For this reason the determination of the decomposition temperatures $\left(T_{\mathrm{d} 5}\right.$ and $T_{\mathrm{d} 10}$ ) has been done considering the starting weight of the sample as the weight detected at $120^{\circ} \mathrm{C}$. The results of $\mathrm{C}_{12}$, $\mathrm{C}_{20}$, and $\mathrm{C}_{22}$ samples, compared with the ones of a standard alkylammonium cation (octadecyltrimethylammonium bromide, ODTA), clearly show the great improvement in thermal stability for $\mathrm{C}_{20}$ and $\mathrm{C}_{22}$, compared with ODTA (Figure 2). In fact, considering as temperature of decomposition the temperature at which the residue percentage reaches $95 \%$ $\left(T_{\mathrm{d} 5}\right)$ or $90 \%\left(T_{\mathrm{d} 10}\right)$ with respect to the initial weight, both $T_{\mathrm{d} 5}$ and $T_{\mathrm{d} 10}$ of the ODTA sample in nitrogen $\left(236^{\circ} \mathrm{C}\right.$ and $\left.245^{\circ} \mathrm{C}\right)$ are clearly lower than the decomposition temperatures of the $\mathrm{C}_{20}$ and $\mathrm{C}_{22}$ samples $\left(265-282^{\circ} \mathrm{C}\right.$ and $264-281^{\circ} \mathrm{C}$, resp.). A similar trend is also observed in the TGA experiment carried out in static air. Moreover, the maximum speed of weight loss during the first stage of decomposition (from DTGA data) for the ODTA is at about $261^{\circ} \mathrm{C}$ while for $\mathrm{C}_{20}$ and $\mathrm{C}_{22}$ it is at 303 and $301^{\circ} \mathrm{C}$, respectively.

Sodium cations in the interlayer space of MMT were exchanged with $\mathrm{C}_{12}, \mathrm{C}_{20}$, and $\mathrm{C}_{18}$, via standard ion exchanges methods [29], to yield o-MMTs (MMT/C $\mathrm{C}_{12}, \mathrm{C}_{20}$, and $\mathrm{C}_{22}$ ). As shown by the XRD patterns (Figure 3) the interlayer $d$ spacings increased with the alkyl chain length. This suggested that the imidazolium surfactants successfully intercalated among the layers of MMTs.

The determination of the surfactant amount intercalated among MMT layers was carried out by TGA and elemental analyses. TGA and DTGA (in static air atmosphere) of organically modified clays are shown in Figure 4. The amount of surfactants was determined from TGA following what was reported in literature [30] and the values were compared with the ones obtained through the elemental nitrogen determination. The results of both determinations were in good agreement and showed the following concentrations of surfactants: $91,94,81$, and $81 \mathrm{meq} / 100 \mathrm{~g}$ clay in ODTA, $\mathrm{C}_{12}$, $\mathrm{C}_{20}$, and $\mathrm{C}_{22}$ /MMT, respectively.

The properties of the nanocomposites obtained by organically modifying the clay with the new surfactants (PS/MMT/ $\mathrm{C}_{20}$ and PS/MMTC ${ }_{22}$ ) were compared with those of samples of virgin PS, of PS unmodified clay microcomposite (PS/ $\mathrm{MMT} / \mathrm{Na}^{+}$), and of a nanocomposite obtained from a clay 


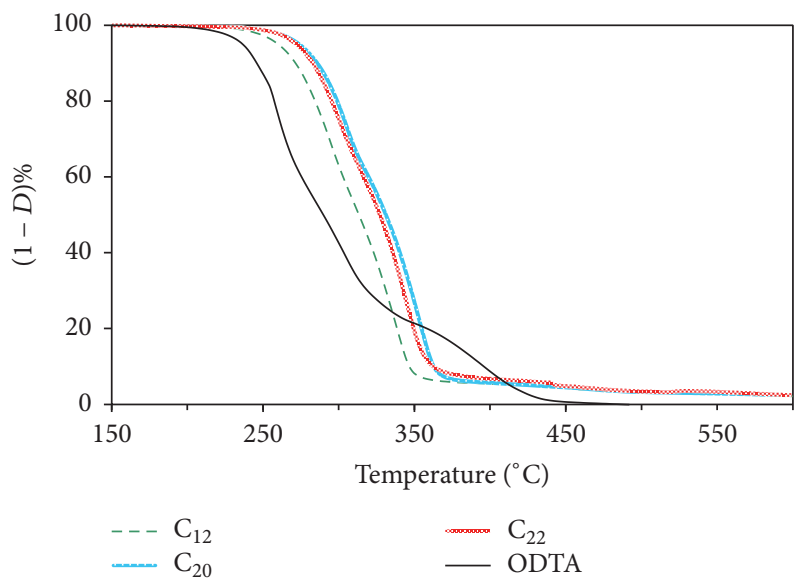

(a)

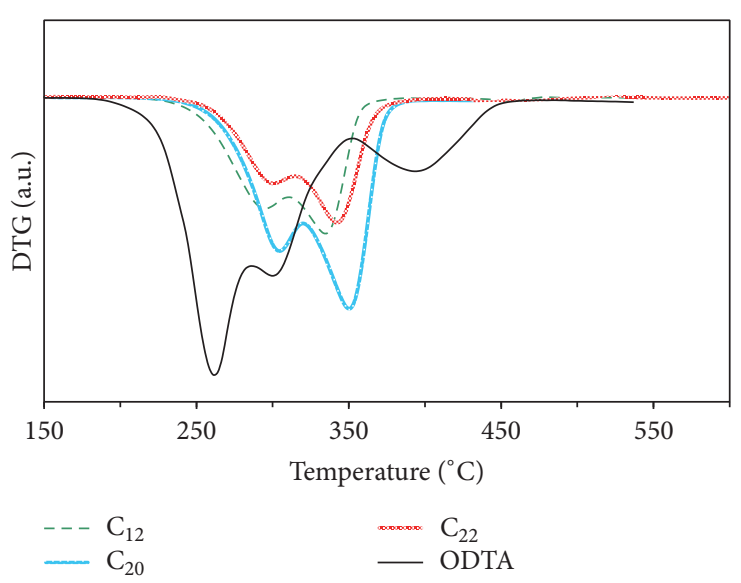

(b)

Figure 2: TGA (a) and DTGA (b) plots of ODTA and $\mathrm{C}_{12}, \mathrm{C}_{20}$, and $\mathrm{C}_{22}$ thermogravimetric analyses in flowing nitrogen atmosphere.

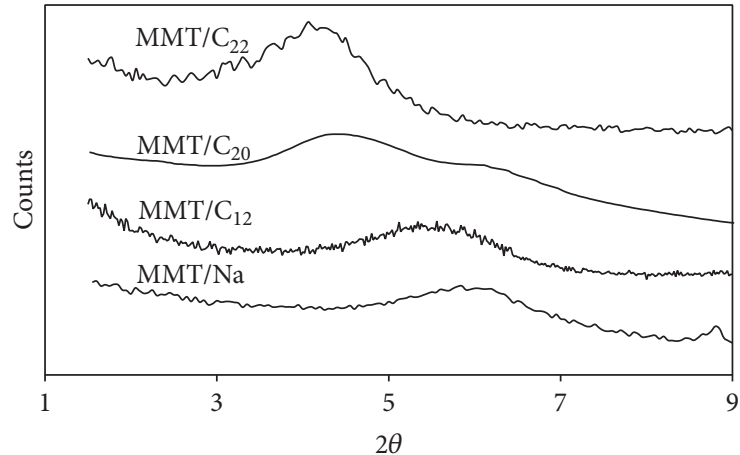

FIGURE 3: XRD patterns of MMT/Na, MMT/ $\mathrm{C}_{12} \mathrm{MMT} / \mathrm{C}_{20}$, and $\mathrm{MMT} / \mathrm{C}_{22}$.

modified with a surfactant having in its imidazole structure a short chain alkyl (PS/MMT/C 12 ) (Scheme 1).

Nanocomposites were characterized through the use of XRD, GPC, TEM, rheological analysis, accelerated aging in Xenotest, and FT-IR.

The XRD analysis of PS/MMT/C $\mathrm{C}_{12}, \mathrm{C}_{20}$, and $\mathrm{C}_{22}$ nanocomposites showed the absence of any diffraction peak thus suggesting a possible exfoliated morphology, while in the case of PS/MMT/ODTA sample the diffraction peak associated with a $d$ value of $4.72 \mathrm{~nm}$, shifted with respect to the value of $2.05 \mathrm{~nm}$ observed in the ODTA/MMT sample, is indicative of the PS intercalation among MMT layers.

TEM micrographs of the ultrathin section of PS/MMT/ ODTA, PS/MMT/C 12 , PS/MMT/C 20 , and PS/MMT/C 22 (Figure $5,40000 \mathrm{x}$ ), where the parallel dark lines represent the intersection of the MMT layers and the grey part represents the PS matrix, were used to get information on the phase morphology. The micrographs of PS/MMT/ODTA sample mainly present an intercalated morphology with stacks containing parallel oriented layers with various degrees of intercalation, and $\mathrm{PS} / \mathrm{MMT} / \mathrm{C}_{12}$ sample micrographs show very few exfoliated layers in the polymer matrix besides intercalated tactoids. In the case of PS/MMT/C 20 and PS/MMT/C 22 micrographs it is possible to identify a nonuniform distribution of the silicate layers in the matrix where individual silicate layers along with two, three, and four layer stacks exfoliating in the PS are present. These results show that the last two samples have a partially exfoliated nanomorphology.

Traditionally, the techniques used to study the dispersion of the clay in the matrix are XRD and TEM. However both have limitations: the former because the absence of diffraction peaks can only reveal a possible exfoliation of the clay and the latter because it can provide information on the morphology of small volume fractions only. We have already shown $[28,31]$ that thermogravimetric studies, by comparing the $E_{a}$ values of the samples, give the possibility of building a qualitative scale of exfoliation and then assist in the characterization of these materials. In the literature it has been shown that rheological analysis is another useful investigation tool to provide information on the state of the dispersion of the clay in the matrix [32]. In this study we have used this tool to characterize our samples. At the outset, in order to assess whether there are influences on the rheological behavior arising from the molecular weight of the matrix, we determined by GPC analysis the average molecular weights of the PS in the different samples.

GPC analysis showed that the presence of organically modified clay during in situ polymerization does not determine an appreciable variation of the average molecular weights and polydispersity $\left(M_{w} / M_{n}\right)$ (Table 1$)$.

Rheological analyses were conducted by recording several frequency sweeps at temperatures ranging from 190 to $220^{\circ} \mathrm{C}$ and analyzing the storage modulus $\left(G^{\prime}\right)$, loss modulus $\left(G^{\prime \prime}\right)$, and complex viscosity $\left(\eta^{*}\right)$.

Considering, first of all, the complex viscosity $\left(\eta^{*}\right)$ data (Figure 6), it is evident that PS and PS/MMT/C 12 samples show quite similar values, while PS/MMT/C ${ }_{20}$ and PS/MMT/ $\mathrm{C}_{22}$ samples show a marked increase in viscosity. These initial results suggest that since the various samples have close values of molecular weight, the different viscosity is due to a different distribution of the clay layers. Then, while PS/MMT/ $\mathrm{C}_{12}$ has a structure close to the one of a microcomposite and it is poorly intercalated, the nanoscale dispersion of modified 


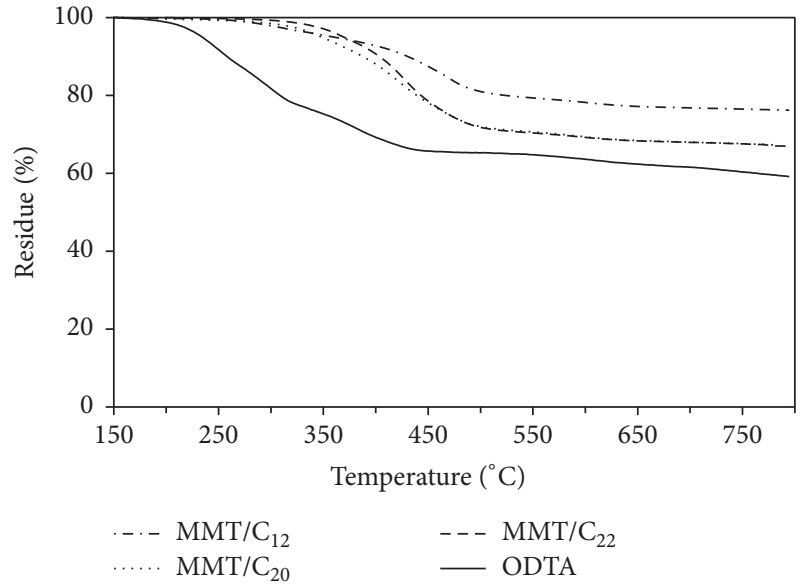

(a)

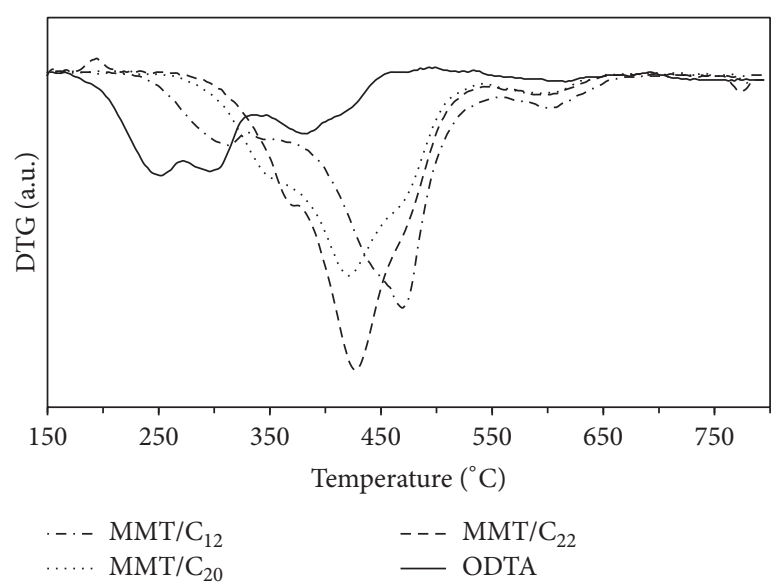

(b)

Figure 4: TGA (a) and DTGA (b) plots of MMT/ODTA, MMT/C $\mathrm{C}_{12}, \mathrm{MMT} / \mathrm{C}_{20}$, and $\mathrm{MMT} / \mathrm{C}_{22}$ thermogravimetric analyses in static air atmosphere.

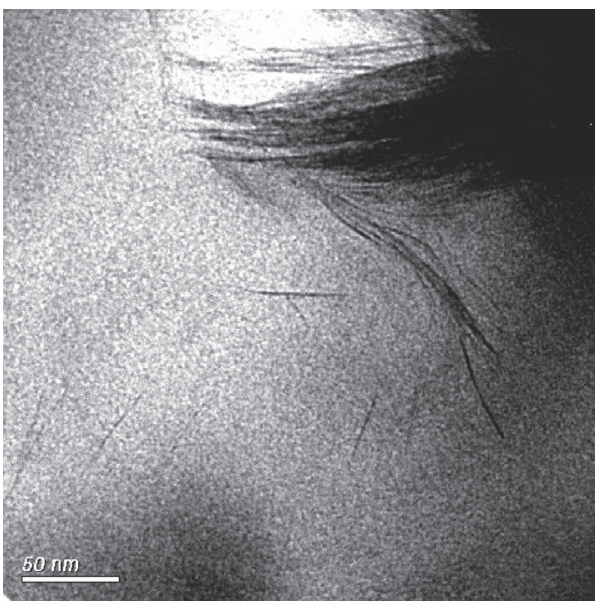

(a)

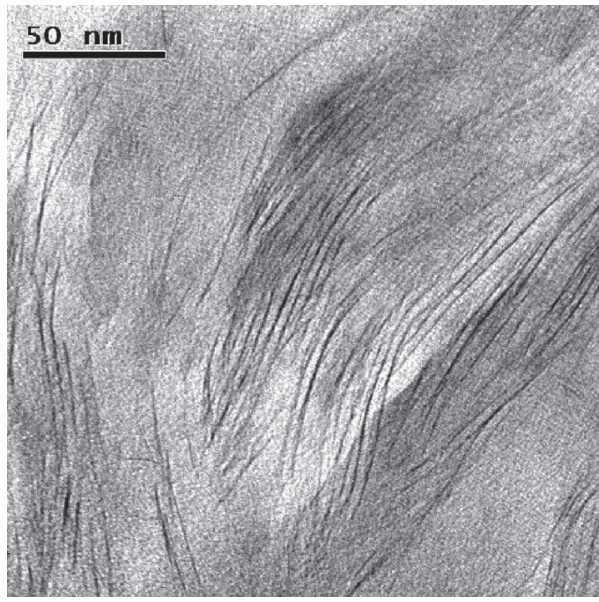

(c)

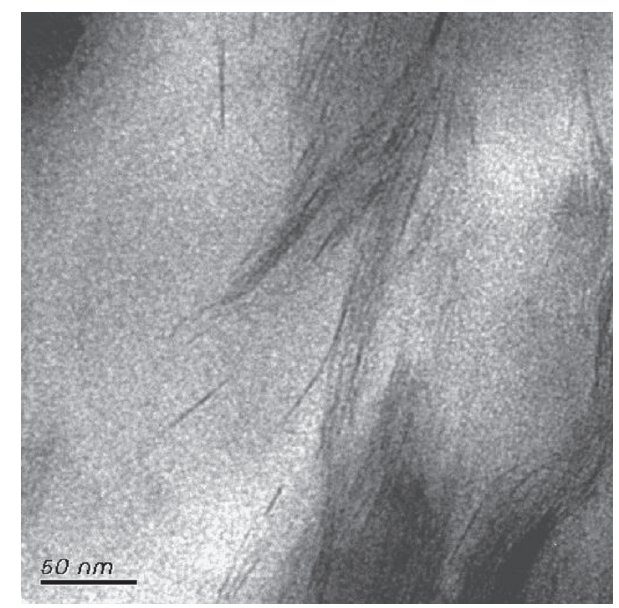

(b)

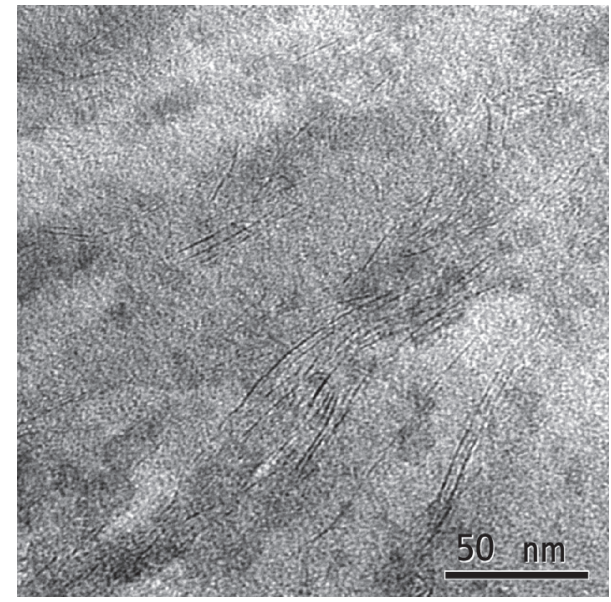

(d)

Figure 5: TEM microphotographs of PS/MMT/ODTA (a), PS/MMT/C ${ }_{12}$ (b), PS/MMT/C 20 (c), and PS/MMT/C 22 (d). 
TABLE 1: Average molecular weights of the PS, PS/MMT/Na ${ }^{+}$, and PS/MMT nanocomposites.

\begin{tabular}{|c|c|c|c|c|c|c|c|}
\hline \multirow{2}{*}{ Sample } & \multicolumn{7}{|c|}{ Average molecular weights } \\
\hline & $M_{p}$ & $M_{n}$ & $M_{w}$ & $M_{z}$ & $M_{z+1}$ & $M_{v}$ & $M_{w} / M_{n}$ \\
\hline PS & $151 \mathrm{k}$ & $136 \mathrm{k}$ & $231 \mathrm{k}$ & $351 \mathrm{k}$ & $475 \mathrm{k}$ & $216 \mathrm{k}$ & 1.70 \\
\hline $\mathrm{PS} / \mathrm{MMT} / \mathrm{Na}^{+}$ & $210 \mathrm{k}$ & $161 \mathrm{k}$ & $261 \mathrm{k}$ & $385 \mathrm{k}$ & $503 \mathrm{k}$ & $245 \mathrm{k}$ & 1.62 \\
\hline $\mathrm{PS} / \mathrm{MMT} / \mathrm{C}_{12}$ & $146 \mathrm{k}$ & $135 \mathrm{k}$ & $221 \mathrm{k}$ & $338 \mathrm{k}$ & $465 \mathrm{k}$ & $206 \mathrm{k}$ & 1.63 \\
\hline $\mathrm{PS} / \mathrm{MMT} / \mathrm{C}_{20}$ & $153 \mathrm{k}$ & $148 \mathrm{k}$ & $227 \mathrm{k}$ & $332 \mathrm{k}$ & $444 \mathrm{k}$ & $214 \mathrm{k}$ & 1.54 \\
\hline $\mathrm{PS} / \mathrm{MMT} / \mathrm{C}_{22}$ & $148 \mathrm{k}$ & $127 \mathrm{k}$ & $213 \mathrm{k}$ & $321 \mathrm{k}$ & $438 \mathrm{k}$ & $199 \mathrm{k}$ & 1.68 \\
\hline
\end{tabular}

TABLE 2: Crossover frequencies and relaxation times of the PS and its nanocomposites at different temperatures $\left({ }^{\circ} \mathrm{C}\right)$.

\begin{tabular}{|c|c|c|c|c|c|c|c|c|}
\hline \multirow[b]{2}{*}{$T\left({ }^{\circ} \mathrm{C}\right)$} & \multicolumn{2}{|c|}{ PS } & \multicolumn{2}{|c|}{$\mathrm{PS} / \mathrm{MMT} / \mathrm{C}_{12}$} & \multicolumn{2}{|c|}{$\mathrm{PS} / \mathrm{MMT} / \mathrm{C}_{20}$} & \multicolumn{2}{|c|}{$\mathrm{PS} / \mathrm{MMT} / \mathrm{C}_{22}$} \\
\hline & $\begin{array}{c}\omega_{x} \\
(\mathrm{rad} / \mathrm{s}) \\
{[\mathrm{Hz}]}\end{array}$ & Relax. time (s) & $\begin{array}{c}\omega_{x} \\
(\mathrm{rad} / \mathrm{s}) \\
{[\mathrm{Hz}]}\end{array}$ & Relax. time (s) & $\begin{array}{c}\omega_{x} \\
(\mathrm{rad} / \mathrm{s}) \\
{[\mathrm{Hz}]}\end{array}$ & Relax. time (s) & $\begin{array}{c}\omega_{x} \\
(\mathrm{rad} / \mathrm{s}) \\
{[\mathrm{Hz}]}\end{array}$ & Relax. time (s) \\
\hline 190 & $\begin{array}{c}20.3 \\
{[3.24]}\end{array}$ & 0.31 & $\begin{array}{c}22.9 \\
{[3.65]}\end{array}$ & 0.27 & $\begin{array}{c}5.9 \\
{[0.93]}\end{array}$ & 1.07 & $\begin{array}{c}1.0 \\
{[0.15]}\end{array}$ & 6.54 \\
\hline 200 & $\begin{array}{c}40.4 \\
{[6.43]}\end{array}$ & 0.16 & $\begin{array}{c}44.2 \\
{[7.04]}\end{array}$ & 0.14 & $\begin{array}{c}11.1 \\
{[1.78]}\end{array}$ & 0.56 & $\begin{array}{c}1.7 \\
{[0.27]}\end{array}$ & 3.74 \\
\hline 210 & $\begin{array}{c}92.3 \\
{[14.7]}\end{array}$ & 0.07 & $\begin{array}{c}73.5 \\
{[11.7]}\end{array}$ & 0.09 & $\begin{array}{c}13.9 \\
{[2.21]}\end{array}$ & 0.45 & $\begin{array}{c}7.61 \\
{[1.21]}\end{array}$ & 0.83 \\
\hline 220 & $\begin{array}{c}115.4 \\
{[18.36]}\end{array}$ & 0.05 & $\begin{array}{c}75.4 \\
{[11.7]}\end{array}$ & 0.09 & $\begin{array}{c}35.8 \\
{[5.70]}\end{array}$ & 0.18 & $\begin{array}{c}12.6 \\
{[2.00]}\end{array}$ & 0.50 \\
\hline
\end{tabular}

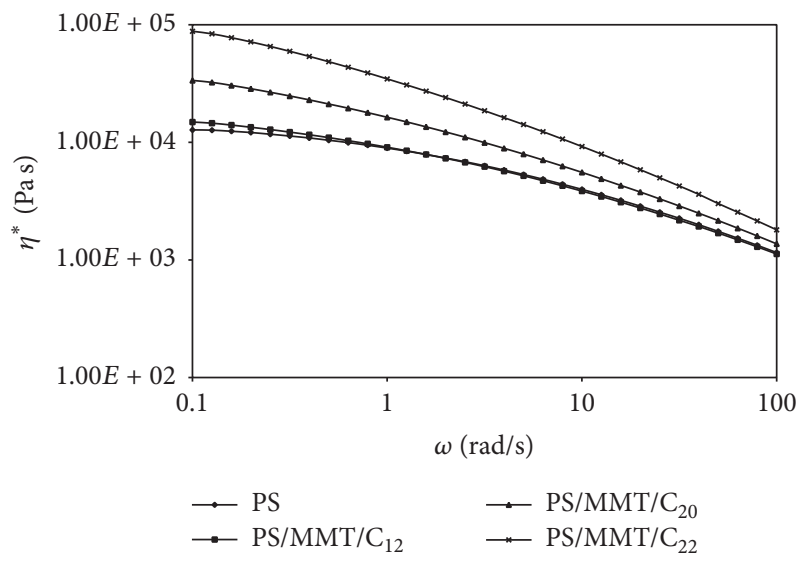

Figure 6: Complex viscosity $\left(\eta^{*}\right)$ at $190^{\circ} \mathrm{C}$ of PS, PS/MMT/C 12 , $\mathrm{PS} / \mathrm{MMT} / \mathrm{C}_{20}$, and $\mathrm{PS} / \mathrm{MMT} / \mathrm{C}_{22}$.

clay nanoplatelets in PS/MMT/C 20 and PS/MMT/C 22 samples gradually increases (higher degree of exfoliation).

Considering now the $G^{\prime}$ and $G^{\prime \prime}$ data, some interesting results emerge. For the polystyrene and its nanocomposites both the elastic and viscous components of the complex modulus show values which testify a mainly viscous behavior at low frequencies $\left(G^{\prime \prime}>G^{\prime}\right)$ and a mainly elastic one at high frequencies $\left(G^{\prime}>G^{\prime \prime}\right)$, with characteristic frequencies at which a reversal of the behavior is achieved (crossover frequency) (Figure 7).

It is known that incorporation of nanofillers in a polymer matrix induces an alteration in molecular mobility and, when present, the crystallinity of the matrix. Polymer nanocomposites exhibit pronounced elastic properties as well as delayed relaxation time as compared to the neat resin [33]. It is therefore logical to expect that as the degree of exfoliation increases, with the consequent increasing of the polymer chain-nanofiller interactions, the molecular mobility is more hindered with a consequent increase of the moduli, especially in the region at low frequencies, and an extension of the interval in which a solid-like viscoelastic behavior prevails.

Then, a better clay exfoliation should promote an increase of moduli and a shift of crossover frequencies toward lower values (delayed relaxation times). This is indeed the trend presented by our samples, with sample PS/MMT/C 22 showing the higher values (Figure 7 and Table 2). The increase of moduli and of relaxation times could be influenced by the average molecular weight. In fact the increase of the average length of the polymer chains is expected to increase the number of entanglements, thus resulting in a decrease of the frequencies at which the chains remain immobilized. Our samples have similar molecular weight and so this contribution must not be considered.

Furthermore, the rheological behavior of a polymer in the molten state is also dependent on the temperature at which the measurement is taken. In fact, the examination of the experimental data shows that as the temperature increases, the absolute values of $G^{\prime}$ and $G^{\prime \prime}$ decrease, even if with different speeds. Naturally, as the temperature increases, the viscous contribution $\left(G^{\prime \prime}\right)$ prevails in a gradually increasing extent with respect to the elastic one $\left(G^{\prime}\right)$ leading to a shift of the crossover frequency toward higher values (Table 2 ). 

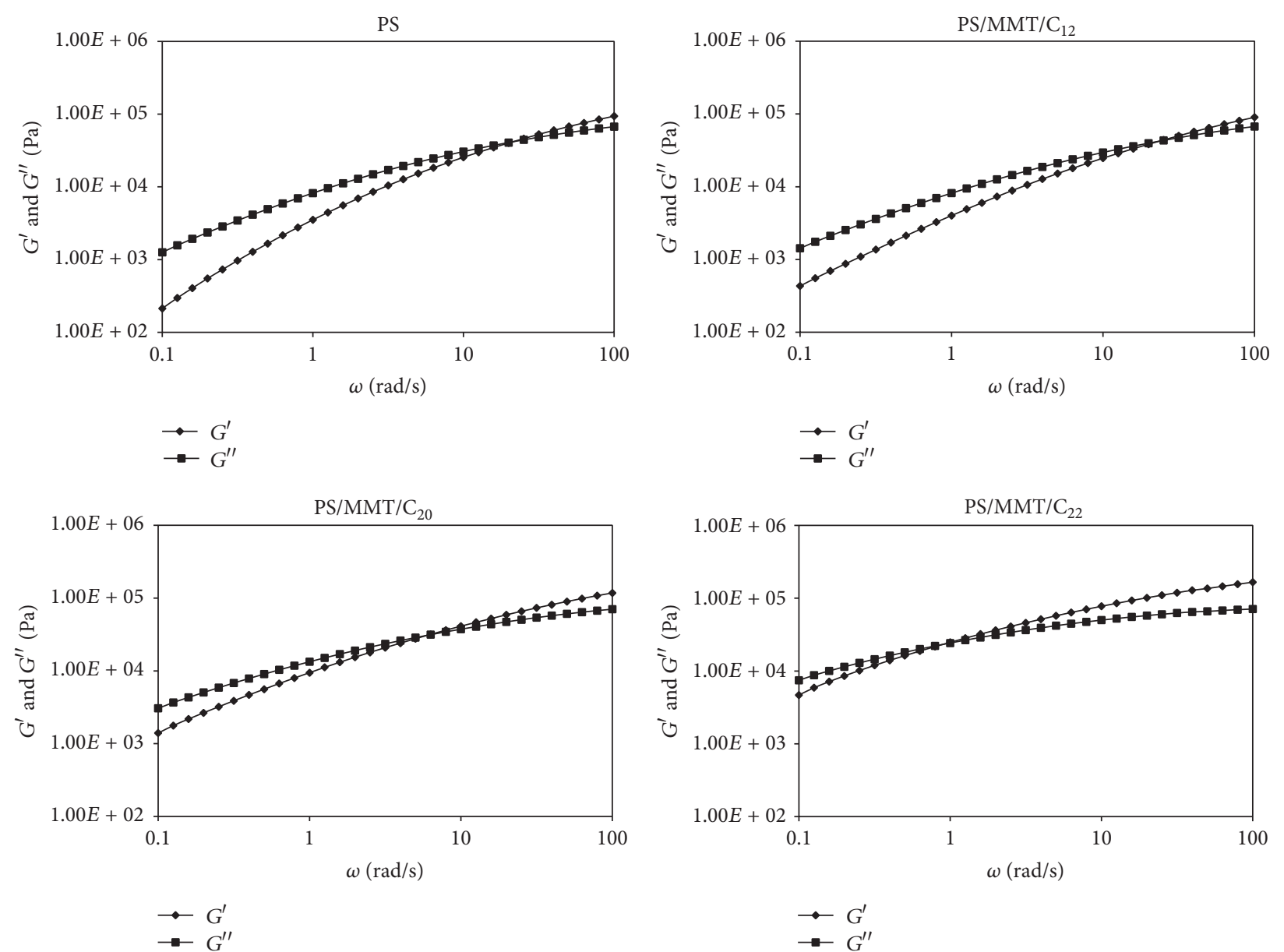

Figure 7: Viscoelastic dynamic moduli (storage modulus $G^{\prime}$ and loss modulus $G^{\prime \prime}$ ) at $190^{\circ} \mathrm{C}$ for PS, PS/MMT/C $12, \mathrm{PS} / \mathrm{MMT} / \mathrm{C}_{20}$, and $\mathrm{PS} / \mathrm{MMT} / \mathrm{C}_{22}$.

This behavior is due to the fact that the micro-Brownian motions of discrete elements of the macromolecular chains are more favored at high temperatures; this implies more macroscopic deformation and the fact that the elastic component prevails at even higher frequencies.

However, observing the results shown by PS and PS/ $\mathrm{MMT} / \mathrm{C}_{12}$ samples, an interesting trend emerges: while in the measurements carried out at lower temperatures (190 and $200^{\circ} \mathrm{C}$ ) PS crossover frequencies values are a little bit lower than the PS/MMT/C 12 ones, at higher temperatures (210 and $220^{\circ} \mathrm{C}$ ) the results are reversed. This result could allow hypothesizing that from one side since in the experiments conducted at 190 and $200^{\circ} \mathrm{C}$ the crossover frequencies, and consequently the relaxation times, are very close in the two samples, both the low concentration of the filler and its poor dispersion do not influence significantly the bulk polystyrene chain mobilities and from the other side that the increase of the macromolecular mobility due to a higher temperature promotes the insertion of polymer chains into clay galleries, slightly increasing the clay dispersion into the matrix.

It is well known that the rheological response of a nanocomposite depends on the number of silicate particles per unit volume within the matrix and on the number of layers of clay per particle of clay.
The difference among the various samples lies in the different chain length of the surfactant used to modify the clay. So it can be assumed that the increase of the chain length in the surfactant promotes the separation of the layers of clay; this leads to a better dispersion of the silicate platelets in the matrix and consequently an increase in aspect ratio.

A confirmation of these results can be drawn from the Cole-Cole plot that can be used as a measure to assess the dispersion of filler into polymer matrix [34]. Since neat polymer and nanocomposites have different morphologies exhibiting different relaxation mechanisms, their Cole-Cole plots, which describe the relationship between the imaginary part $\eta^{\prime \prime}$ (= $\left.G^{\prime} / \omega\right)$ and the real part $\eta^{\prime}\left(=G^{\prime \prime} / \omega\right)$ of $\eta^{*}$, should display different shapes. Figure 8 displays the Cole-Cole plots of PS and its nanocomposites. While, as expected, PS plot presents a circular arc shape, the other samples present plots deviating from an arc-like shape. Since the deviation from an arclike shape in the Cole-Cole plot is a measure of solid-like behavior, in our case deriving from a more efficient hindrance of polymer chains motion due to an increase of the number of clay platelets produced by exfoliation, we can conclude that the degree of exfoliation follows the order PS/MMT/C $\mathrm{C}_{22}>$ $\mathrm{PS} / \mathrm{MMT} / \mathrm{C}_{20}>\mathrm{PS} / \mathrm{MMT} / \mathrm{C}_{12}$, as already hypothesized from complex viscosity, moduli, and relaxation time data. 
TABLE 3: Average molecular weights of PSox, PS/MMT/ $\mathrm{Na}^{+}$ox, and oxidized nanocomposites.

\begin{tabular}{|c|c|c|c|c|c|c|c|c|}
\hline \multirow{2}{*}{ Sample } & \multicolumn{8}{|c|}{ Average molecular weights } \\
\hline & $M_{p}$ & $M_{n}$ & $M_{w}$ & $M_{z}$ & $M_{z+1}$ & $M_{v}$ & $M_{w} / M_{n}$ & SI \\
\hline PSox & $87 \mathrm{k}$ & $18 \mathrm{k}$ & $66 \mathrm{k}$ & $122 \mathrm{k}$ & $172 \mathrm{k}$ & $58 \mathrm{k}$ & 3.61 & 6.47 \\
\hline $\mathrm{PS} / \mathrm{MMT} / \mathrm{Na}^{+}$ox & $94 \mathrm{k}$ & $34 \mathrm{k}$ & $78 \mathrm{k}$ & $124 \mathrm{k}$ & $164 \mathrm{k}$ & $72 \mathrm{k}$ & 2.30 & 3.74 \\
\hline $\mathrm{PS} / \mathrm{MMT} / \mathrm{C}_{12}$ ox & $88 \mathrm{k}$ & $23 \mathrm{k}$ & $66 \mathrm{k}$ & $118 \mathrm{k}$ & $163 \mathrm{k}$ & $59 \mathrm{k}$ & 2.89 & 4.91 \\
\hline $\mathrm{PS} / \mathrm{MMT} / \mathrm{C}_{20}$ ox & $86 \mathrm{k}$ & $16 \mathrm{k}$ & $59 \mathrm{k}$ & $112 \mathrm{k}$ & $157 \mathrm{k}$ & $52 \mathrm{k}$ & 3.61 & 8.07 \\
\hline $\mathrm{PS} / \mathrm{MMT} / \mathrm{C}_{22}$ ox & $86 \mathrm{k}$ & $16 \mathrm{k}$ & $58 \mathrm{k}$ & $109 \mathrm{k}$ & $154 \mathrm{k}$ & $51 \mathrm{k}$ & 3.72 & 7.17 \\
\hline
\end{tabular}

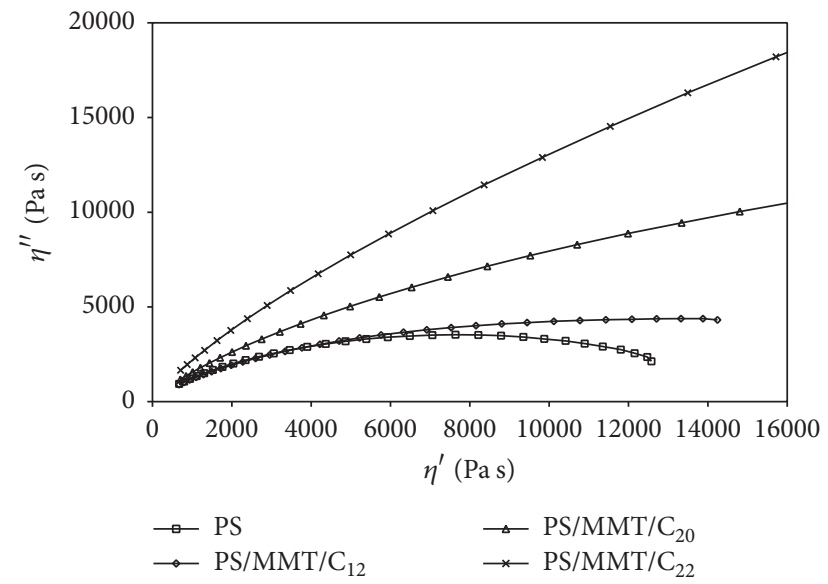

Figure 8: Cole-Cole plots at $190^{\circ} \mathrm{C}$ for PS, PS/MMT/C 12 , PS/MMT/ $\mathrm{C}_{20}$, and $\mathrm{PS} / \mathrm{MMT} / \mathrm{C}_{22}$.

Films of all the samples were prepared with a thickness of 100 microns in order to be subjected to UV accelerated aging test in a Xenotest. The experiment was conducted for 400 hours and the evolution of the process of photodegradation was followed by registration of the infrared spectra. At the end of the aging stage, GPC analyses were carried out. A decrease of the average molecular weights was observed following the photodegradation process. The magnitude of this reduction does not seem to be influenced by the presence of the clay.

However, it is interesting to note that the polydispersity index in the virgin samples does not differ significantly among the various samples (Table 1) while, after the photodegradation, it increases to a much lesser extent in case of microcomposite (PS/MMT/ $/ \mathrm{Na}^{+}$) and to a much more pronounced extent, in proportion to the clay exfoliation degree (and then to the length of the alkyl chain present in the structure of the surfactant), in the nanocomposites obtained with imidazole surfactants (Table 3 ).

Studying the molecular weight changes on the basis of the scission index (SI), which is defined as the number of broken bonds per initial macromolecule [35] according to

$$
\mathrm{SI}=\frac{\left[n(t)-n\left(t_{0}\right)\right]}{n\left(t_{0}\right)}=\left[\frac{M_{n}\left(t_{0}\right)}{M_{n}(t)}\right]-1,
$$

some interesting results emerged.

The data reported in Table 3 show the overall changes in the SI at the end of the photodegradation. It is known that polymer photodegradation involves two processes: chain scission and/or crosslinking, which changes the molecular weight $\left(M_{n}\right.$ and $M_{w}$, number and weight average molecular weight resp.). In the absence of crosslinking, only main chain scissions occur and the $M_{n}$ and $M_{w}$ drift toward smaller values. For random scission, polydispersity index $\left(M_{w} / M_{n}\right)$ tends to 2. If simultaneous chain scission and crosslinking reactions occur and the probability of chain scission is smaller than the probability of crosslinking, $M_{w} / M_{n}$ increases [36]. From the data for PS films reported in Table 3, it was evident that $M_{w} / M_{n}$ had increased indicating that chain scission and crosslinking reactions were simultaneous with a probability of chain scission smaller than the probability of crosslinking. This indicated that the degradation took place with simultaneous occurrence both of branching reactions, which produced higher molecular weight molecules, and of chain scissions but with different trends: the presence of unmodified clay (sample PS/MMT/ $/ \mathrm{Na}^{+}$ox) seems to partially inhibit crosslinking, while as the degree of exfoliation increases, with a consequent increasing of polystyrene-surfactant interactions, the branching reactions become even more probable.

With regard to the kinetics of the UV photodegradation, it is already known that, with the proceeding of polystyrene UV accelerated aging, the formation of bands due to the hydroxyl groups ( 3600 to $3330 \mathrm{~cm}^{-1}$ ) and carbonyl groups (1800$1600 \mathrm{~cm}^{-1}$ and $\left.1250 \mathrm{~cm}^{-1}\right)$ is observed. This trend is observed in all our samples, but with different kinetics.

First of all, the microcomposite behavior (where no surfactant is present) shows an interesting feature emerging during the very first hours of accelerated aging: the rapid increasing, with respect to neat polystyrene, of several peaks among which the more important ones are centered at 1690 , 1704, and $1732 \mathrm{~cm}^{-1}$ (Figure 9). As reported by Mailhot and Gardette [37] in their study on polystyrene photooxidation, these peaks can be assigned to the increase of concentration of aromatic ketones, benzaldehyde, and $\delta$-lactone, respectively. This rapid growth has to be attributed to a catalytic action of sites present in the clay.

The kinetic curves (Figure 10), obtained plotting the carbonyl band area variation as a function of exposure time, show that the rate of photooxidation of all the clay containing samples is higher with respect to neat polystyrene sample. The rate is higher as a function of the degree of dispersion of the filler in the polymer matrix and then it increases with the increasing alkyl chain length present in the structure of the surfactant. In fact, the samples having the highest degree of dispersion of the silicate layers in the polymer matrix, that is, 


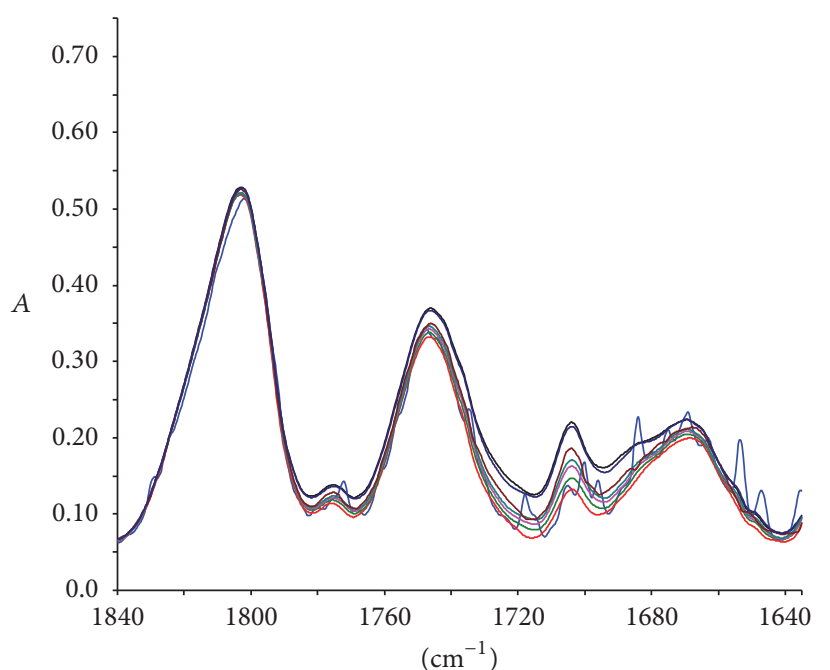

(a)

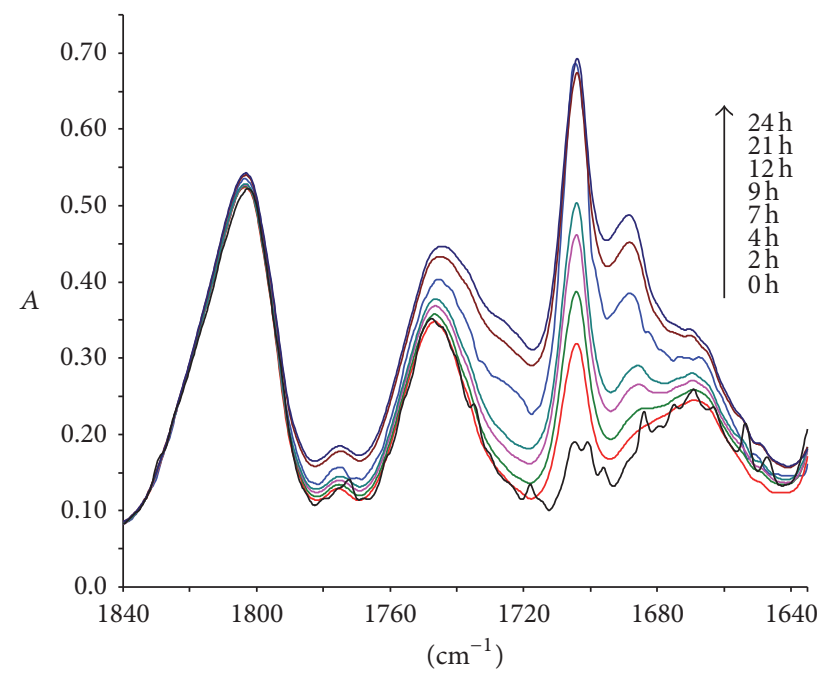

(b)

FIGURE 9: Variation of the area of carbonyl band during the very early stage of photooxidation (0-24h) of PS (a) and PS/MMT/Na ${ }^{+}$(b).

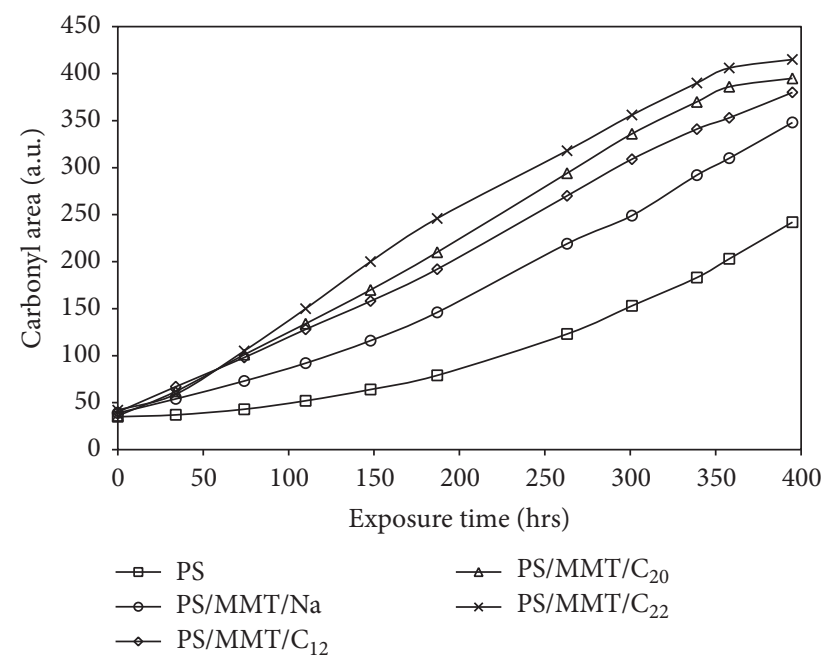

FIGURE 10: Variations of the carbonyl band area during the photooxidation of PS, PS/MMT/Na, PS/MMT/C 12 , PS/MMT/C ${ }_{20}$, and $\mathrm{PS} / \mathrm{MMT} / \mathrm{C}_{22}$.

the $\mathrm{PS} / \mathrm{MMT} / \mathrm{C}_{20}$ and $\mathrm{PS} / \mathrm{MMT} / \mathrm{C}_{22}$ samples, degrade faster than the PS/MMT/C 12 one, with the microcomposite (PS/ $\mathrm{MMT} / \mathrm{Na}^{+}$) showing a relatively lower rate.

\section{Conclusions}

The preparation of montmorillonite/PS nanocomposites by the use of two new thermally stable imidazolium surfactants $\left(\mathrm{C}_{20}\right.$ and $\left.\mathrm{C}_{22}\right)$ showed that it is possible to increase the exfoliation degree by increasing the length of the alkyl chain present in thermally stable surfactant structure. The higher exfoliation degree allows hindering more efficiently the macromolecular motion determining an increase of the relaxation times of the polymer melt and of its viscosity. In addition, a higher exfoliation promotes faster UV degradation of the nanocomposite that can depend on both higher polymerclay interactions (especially during the very first hours of UV exposure) and higher polymer-surfactants interactions. Studies are in progress to address the contribution deriving from the structure of the surfactants to the enhanced UV photodegradation and to test other properties that have strong interest from an application point of view as, for example, mechanical performance, fire resistance, or barrier properties of the nanocomposites prepared starting from clay organically modified with these new surfactants in other properties.

\section{Competing Interests}

The authors declare that they have no competing interests.

\section{Acknowledgments}

The authors gratefully acknowledge the support of this work by University of Catania through PRA funding and Dr. Elena Fabbri for TEM microphotographs.

\section{References}

[1] S. Sinha Ray and M. Okamoto, "Polymer/layered silicate nanocomposites: a review from preparation to processing," Progress in Polymer Science, vol. 28, no. 11, pp. 1539-1641, 2003.

[2] H. Kim, A. A. Abdala, and C. W. MacOsko, "Graphene/polymer nanocomposites," Macromolecules, vol. 43, no. 16, pp. 65156530, 2010.

[3] Z. Spitalsky, D. Tasis, K. Papagelis, and C. Galiotis, "Carbon nanotube-polymer composites: chemistry, processing, mechanical and electrical properties," Progress in Polymer Science, vol. 35, no. 3, pp. 357-401, 2010.

[4] S. Sachse, F. Silva, H. Zhu et al., "The effect of nanoclay on dust generation during drilling of PA6 nanocomposites," Journal of Nanomaterials, vol. 2012, Article ID 189386, 8 pages, 2012. 
[5] M. Alshabanat, A. Al-Arrash, and W. Mekhamer, "Polystyrene/ montmorillonite nanocomposites: study of the morphology and effects of sonication time on thermal stability," Journal of Nanomaterials, vol. 2013, Article ID 650725, 12 pages, 2013.

[6] N. Aït Hocine, "Mechanical property enhancement of polymer nanocomposites," in Optimization of Polymer Nanocomposite Properties, V. Mittal, Ed., pp. 123-138, Wiley-VCH Verlag GmbH \& Co. KGaA, 2010.

[7] S. P. Fillery, H. Koerner, L. Drummy et al., "Nanolaminates: increasing dielectric breakdown strength of composites," ACS Applied Materials \& Interfaces, vol. 4, no. 3, pp. 1388-1396, 2012.

[8] J.-W. Rhim, H.-M. Park, and C.-S. Ha, "Bio-nanocomposites for food packaging applications," Progress in Polymer Science, vol. 38, no. 10-11, pp. 1629-1652, 2013.

[9] NN., Auto applications drive commercialization of nanocomposites, polymer additives colors, 2002, http://www.specialchem4polymers.com/resources/articles/article.aspx?id=579.

[10] BCC Research Report, Global Markets for Nanocomposites, Nanoparticles, Nanoclays, and Nanotubes, 2014.

[11] P. Kiliaris and C. D. Papaspyrides, "Polymer/layered silicate (clay) nanocomposites: an overview of flame retardancy," Progress in Polymer Science, vol. 35, no. 7, pp. 902-958, 2010.

[12] T. D. Fornes, P. J. Yoon, D. L. Hunter, H. Keskkula, and D. R. Paul, "Effect of organoclay structure on nylon 6 nanocomposite morphology and properties," Polymer, vol. 43, no. 22, pp. 59155933, 2002.

[13] H. Dalir, R. D. Farahani, V. Nhim, B. Samson, M. Lévesque, and D. Therriault, "Preparation of highly exfoliated polyester-clay nanocomposites: process-property correlations," Langmuir, vol. 28, no. 1, pp. 791-803, 2012.

[14] W. Xie, Z. Gao, K. Liu et al., “Thermal characterization of organically modified montmorillonite," Thermochimica Acta, vol. 367-368, pp. 339-350, 2001.

[15] M. Sepehr, L. A. Utracki, X. Zheng, and C. A. Wilkie, "Polystyrenes with macro-intercalated organoclay. Part II. Rheology and mechanical performance," Polymer, vol. 46, no. 25, pp. 11569-11581, 2005.

[16] R. Pfaendner, "Nanocomposites: industrial opportunity or challenge?” Polymer Degradation and Stability, vol. 95, no. 3, pp. 369-373, 2010.

[17] R. K. Shah and D. R. Paul, "Organoclay degradation in melt processed polyethylene nanocomposites," Polymer, vol. 47, no. 11, pp. 4075-4084, 2006.

[18] V. Mittal, "Modification of montmorillonites with thermally stable phosphonium cations and comparison with alkylammonium montmorillonites," Applied Clay Science, vol. 56, pp. 103109, 2012.

[19] M. Yousfi, J. Soulestin, B. Vergnes, M. F. Lacrampe, and P. Krawczak, "Morphology and mechanical properties of PET/PE blends compatibilized by nanoclays: effect of thermal stability of nanofiller organic modifier," Journal of Applied Polymer Science, vol. 128, no. 5, pp. 2766-2778, 2013.

[20] G. Chigwada, D. Wang, and C. A. Wilkie, "Polystyrene nanocomposites based on quinolinium and pyridinium surfactants," Polymer Degradation and Stability, vol. 91, no. 4, pp. 848-855, 2006.

[21] F. A. Bottino, E. Fabbri, I. L. Fragalà et al., "Polystyrene-clay nanocomposites prepared with polymerizable imidazolium surfactants," Macromolecular Rapid Communications, vol. 24, no. 18, pp. 1079-1084, 2003.
[22] G. Cai, J. Feng, J. Zhu, and C. A. Wilkie, "Polystyrene- and poly (methyl methacrylate)-organoclay nanocomposites using a one-chain benzimidazolium surfactant," Polymer Degradation and Stability, vol. 99, no. 1, pp. 204-210, 2014.

[23] C. F. P. Oliveira, S. R. Cremm, G. H. S. Cruz, and G. J. M. Fechine, "Photostabilization of polystyrene/montmorillonite nanocomposite. A factorial experimental design 24," Journal of Applied Polymer Science, vol. 128, no. 1, pp. 188-198, 2013.

[24] P.-O. Bussière, J. Peyroux, G. Chadeyron, and S. Therias, "Influence of functional nanoparticles on the photostability of polymer materials: recent progress and further applications," Polymer Degradation and Stability, vol. 98, no. 12, pp. 2411-2418, 2013.

[25] N. T. Dintcheva, G. Filippone, F. P. La Mantia, and D. Acierno, "Photo-oxidation behaviour of polyethylene/polyamide 6 blends filled with organomodified clay: improvement of the photoresistance through morphology modification," Polymer Degradation and Stability, vol. 95, no. 4, pp. 527-535, 2010.

[26] S. Morlat-Therias, B. Mailhot, D. Gonzalez, and J.-L. Gardette, "Photooxidation of polypropylene/montmorillonite nanocomposites. 2. Interactions with antioxidantss," Chemistry of Materials, vol. 17, no. 5, pp. 1072-1078, 2005.

[27] H. Qin, S. Zhang, H. Liu, S. Xie, M. Yang, and D. Shen, "Photooxidative degradation of polypropylene/montmorillonite nanocomposites," Polymer, vol. 46, no. 9, pp. 3149-3156, 2005.

[28] A. Pollicino, F. A. Bottino, G. Di Pasquale, E. Fabbri, and A. Orestano, "Influence of montmorillonite nano-dispersion on polystyrene photo-oxidation," Polymer Degradation and Stability, vol. 94, no. 3, pp. 369-374, 2009.

[29] R. A. Vaia, R. K. Teukolsky, and E. P. Giannelis, "Interlayer structure and molecular environment of alkylammonium layered silicates," Chemistry of Materials, vol. 6, no. 7, pp. 1017-1022, 1994.

[30] A. Vazquez, M. López, G. Kortaberria, L. Martín, and I. Mondragon, "Modification of montmorillonite with cationic surfactants. Thermal and chemical analysis including CEC determination," Applied Clay Science, vol. 41, no. 1-2, pp. 24-36, 2008.

[31] G. Di Pasquale and A. Pollicino, "PMMA/o-MMT nanocomposites obtained using thermally stable surfactants," Journal of Applied Polymer Science, vol. 132, no. 5, Article ID 41393, 2015.

[32] J. Zhao, A. B. Morgan, and J. D. Harris, "Rheological characterization of polystyrene-clay nanocomposites to compare the degree of exfoliation and dispersion," Polymer, vol. 46, no. 20, pp. 8641-8660, 2005.

[33] S. Banerjee, M. Joshi, and A. K. Ghosh, "Investigations on clay dispersion in polypropylene/clay nanocomposites using rheological and microscopic analysis," Journal of Applied Polymer Science, vol. 130, no. 6, pp. 4464-4473, 2013.

[34] I. Janigová, F. Lednický, D. J. Mošková, and I. Chodák, "Nanocomposites with biodegradable polycaprolactone matrix," Macromolecular Symposia, vol. 301, no. 1, pp. 1-8, 2011.

[35] M. A. Semsarzadeh and H. Salehi, "Autoxidation of polypropylene glycol and its catalysis with ferric acetylacetonate," European Polymer Journal, vol. 36, no. 5, pp. 1001-1010, 2000.

[36] C. David, M. Trojan, A. Daro, and W. Demarteau, "Photodegradation of polyethylene: comparison of various photoinitiators in natural weathering conditions," Polymer Degradation and Stability, vol. 37, no. 3, pp. 233-245, 1992.

[37] B. Mailhot and J. L. Gardette, "Polystyrene photooxidation. 1. Identification of the IR-absorbing photoproducts formed at short and long wavelengths," Macromolecules, vol. 25, no. 16, pp. 4119-4126, 1992. 

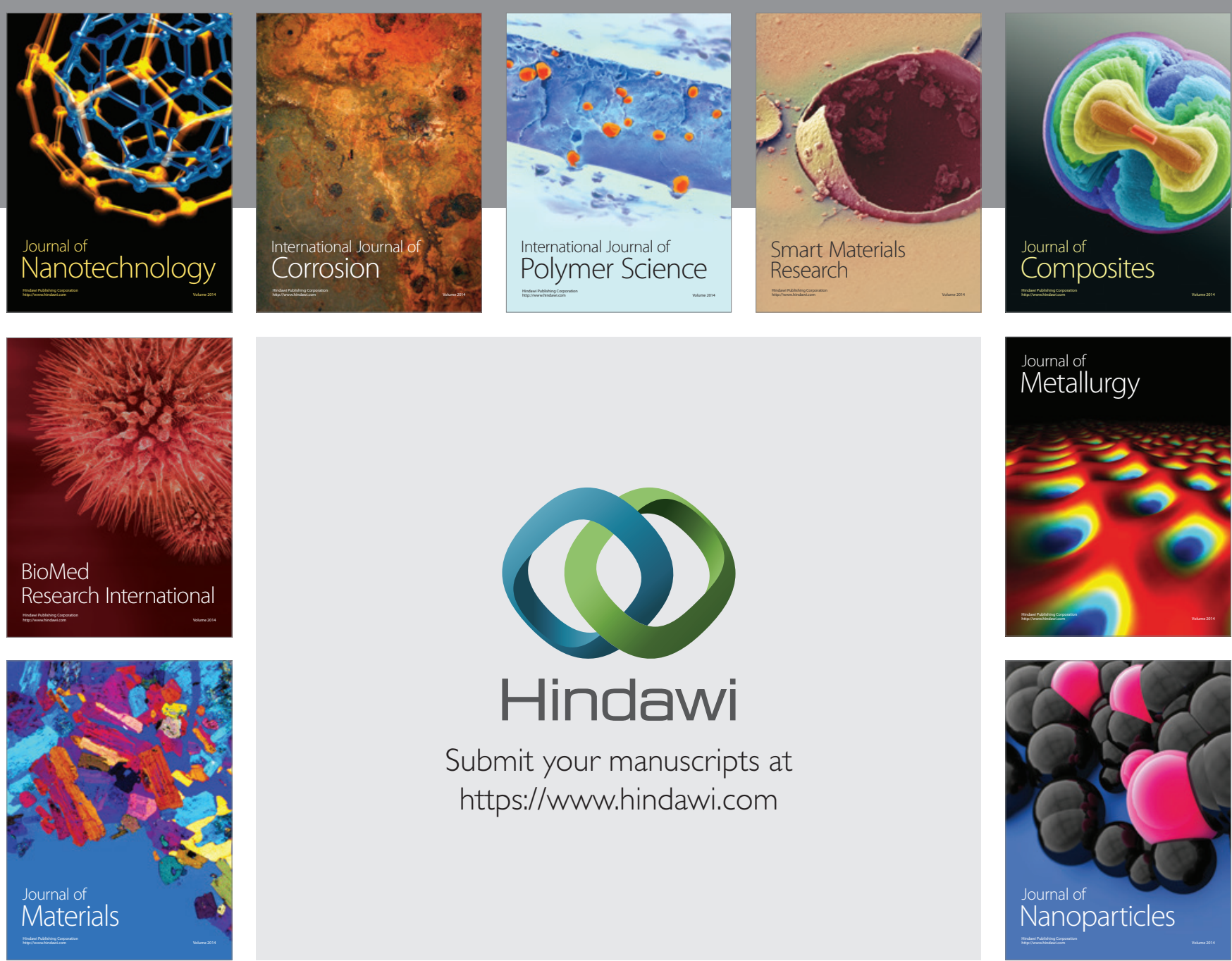

\section{Hindawi}

Submit your manuscripts at

https://www.hindawi.com

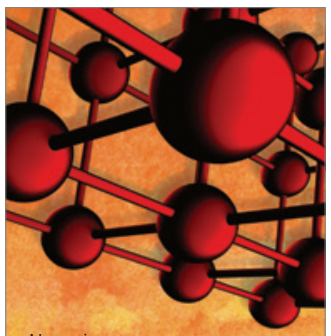

Materials Science and Engineering
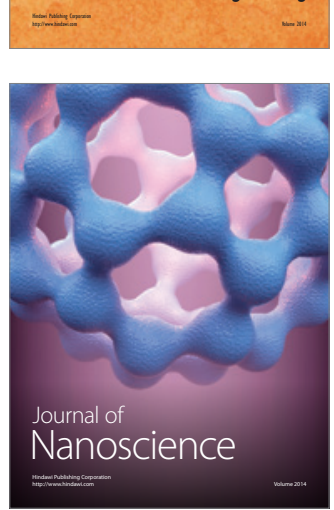
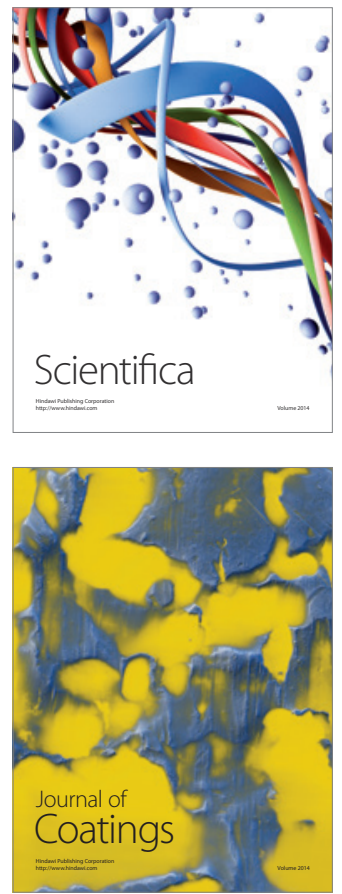
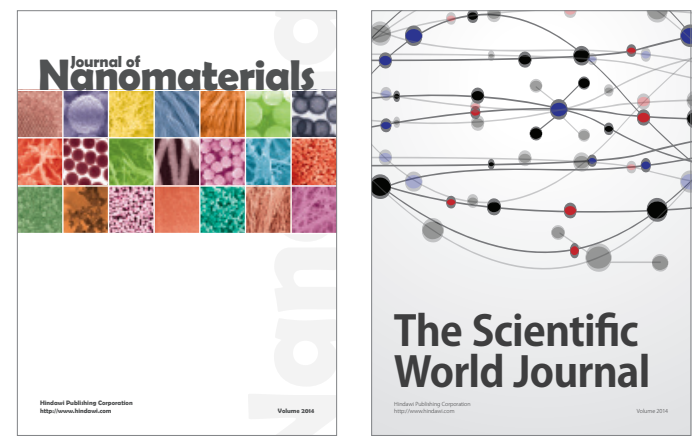

The Scientific World Journal
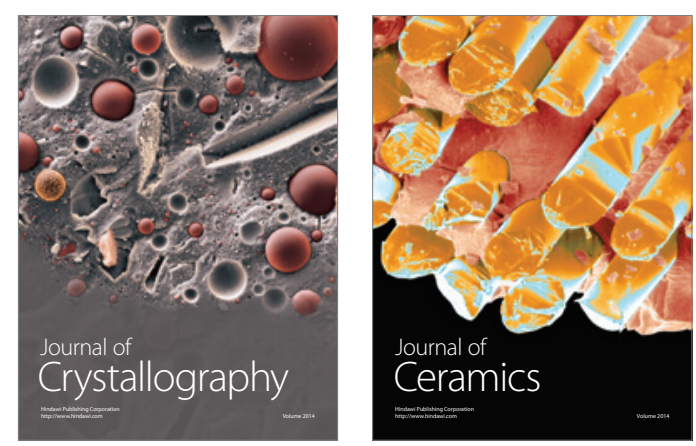
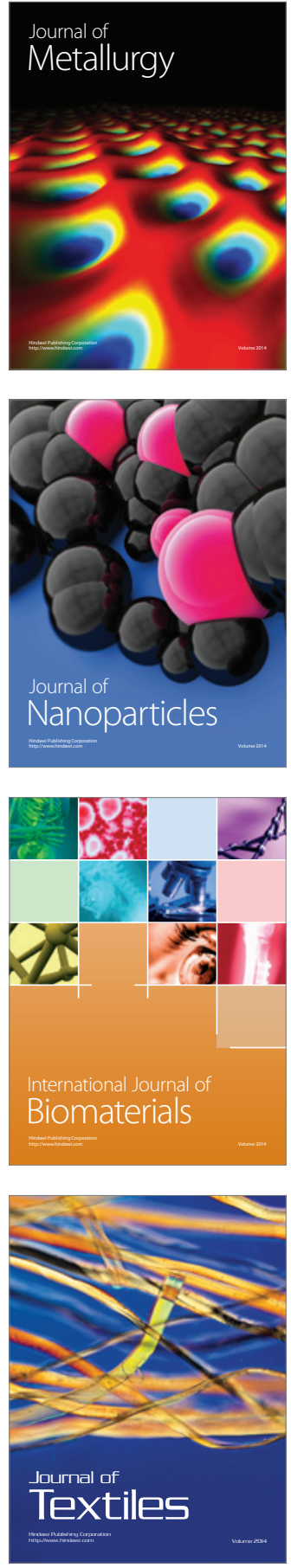